J. Dairy Sci. 97:5592-5598

http://dx.doi.org/10.3168/jds.2014-7947

(C) American Dairy Science Association ${ }^{\circledR}, 2014$.

\title{
Short communication: Comparing real-time PCR and bacteriological cultures for Streptococcus agalactiae and Staphylococcus aureus in bulk-tank milk samples
}

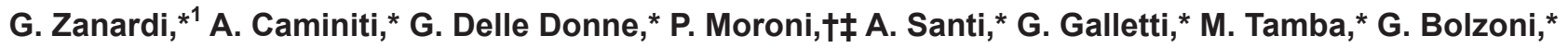 \\ and L. Bertocchi* \\ *Istituto Zooprofilattico Sperimentale Lombardia ed Emilia-Romagna, Via Bianchi 9, 25124, Brescia, Italy \\ †Università degli Studi di Milano, Dipartimento di Scienze Veterinarie per la Salute, la Produzione Animale e la Sicurezza Alimentare, \\ Via Celoria 10, 20133 Milan, Italy \\ $\ddagger$ Animal Health Diagnostic Center, Quality Milk Production Services, Cornell University, 240 Farrier Road, Ithaca, NY 14853
}

\begin{abstract}
For more than $30 \mathrm{yr}$, a control plan for Streptococcus agalactiae and Staphylococcus aureus has been carried out in more than 1,500 dairy herds of the province of Brescia (northern Italy). From 2010 to 2011, the apparent prevalence of Strep. agalactiae has been relatively stable around $10 \%$, but the apparent prevalence of Staph. aureus has been greater than $40 \%$ with an increasing trend. The aim of this paper was to estimate and compare the diagnostic accuracy of 3 assays for the detection of Strep. agalactiae and Staph. aureus in bulk-tank milk samples (BTMS) in field conditions. The assays were a qualitative and a quantitative bacteriological culture (BC) for each pathogen and a homemade multiplex real-time PCR (rt-PCR). Because a gold standard was not available, the sensitivities (Se) and specificities (Sp) were evaluated using a Bayesian latent class approach. In 2012 we collected one BTMS from 165 dairy herds that were found positive for Strep. agalactiae in the previous 2-yr campaigns of eradication plan. In most cases, BTMS collected in these herds were positive for Staph. aureus as well, confirming the wide spread of this pathogen. At the same time we also collected composite milk samples from all the 8,624 lactating cows to evaluate the within-herd prevalence of Strep. agalactiae. Streptococcus agalactiae samples were cultured using a selective medium Tallium Kristalviolette Tossin, whereas for Staph. aureus, we used Baird Parker modified medium with added Rabbit Plasma Fibrinogen ISO-Formulation. In parallel, BTMS were tested using the rt-PCR. Regarding Strep. agalactiae, the posterior median of $\mathrm{Se}$ and $\mathrm{Sp}$ of the $2 \mathrm{BC}$ was similar [qualitative $\mathrm{BC}: \mathrm{Se}=98 \%$, posterior credible interval (95\%PCI): $94-100 \%$, and $\mathrm{Sp}=99 \%$, 95\%PCI: 96-100\%; quantitative BC: $\mathrm{Se}=99 \%, 95 \%$ PCI: $96-$
\end{abstract}

Received January 15, 2014.

Accepted May 25, 2014.

${ }^{1}$ Corresponding author: giorgio.zanardi@izsler.it
$100 \%$, and $\mathrm{Sp}=99 \%, 95 \%$ PCI: $95-100 \%]$ and higher than those of the rt-PCR (at 40 cycle threshold, Se = 92\%, 95\%PCI: 85-97\%; Sp = 94\%, 95\%PCI: 88-98\%). Also in case of Staph. aureus, the posterior medians of BC were generally higher than those of rt-PCR. In fact, although the Se of BC was slightly lower (rt-PCR at 40 cycle threshold, median $\mathrm{Se}=99 \%, 95 \%$ PCI: $97-$ $100 \%$, and qualitative BC, median $\mathrm{Se}=94 \%, 95 \%$ PCI: $87-99 \%$ ), the Sp was much higher (rt-PCR at 40 cycle threshold, median $\mathrm{Sp}=67 \%$, 95\%PCI: 38-97\%; qualitative BC, median $\mathrm{Sp}=95 \%$; 95\%PCI: 76-100\%). Our study confirms that BC and rt-PCR are reliable diagnostic tools to detect Strep. agalactiae and Staph. aureus, and rt-PCR results should be confirmed by BC carried out on BTMS and possibly on composite milk samples.

Key words: bulk-tank milk sample, bacteriological culture, real-time PCR

\section{Short Communication}

Streptococcus agalactiae and Staphylococcus aureus are a cause of IMI and represent a significant economic problem because of milk production losses (Keefe et al., 1997; Schukken et al., 2009). The primary reservoir of these pathogens is the infected udder, from which the infection spreads between quarters and among cows during the milking process (Eberhart et al., 1987). Infections are typically subclinical and chronic but sometimes are characterized by clinical episodes (Smith and Hogan, 1995).

For more than 30 yr, a control plan for Strep. agalactiae IMI has been carried out on bulk-tank milk samples (BTMS) in dairy herds of the province of Brescia (Lombardy region, northern Italy). The province of Brescia extends over $4,770 \mathrm{~km}^{2}$, and the dairy cow population is almost 161,000 in about 1,500 herds. The annual milk production is $120,000 \mathrm{t}$, which accounts for some $10 \%$ of the national production. 
Streptococcus agalactiae is a $\beta$-hemolytic gram-positive Streptococcus, and it is a highly contagious obligate parasite of the bovine mammary gland. For this reason eradication is achievable by means of milking hygiene practices, suitable dry-cow therapy, culling of refractory cases, and the application of biosecurity measures. In the last $2 \mathrm{yr}$, the apparent herd prevalence of Strep. agalactiae (calculated as the proportion of herds where at least one BTMS was positive for Strep. agalactiae out of the total number of herds) has been low and stable in the province of Brescia. In 2010 the apparent herd prevalence was $8.6 \%[8.6 \%=(113 / 1,315) \times 100$; $95 \%$ CI: $7.1-10.1 \%]$, and in 2011 it was $10.6 \%$ [10.6\% = $(155 / 1456) \times 100 ; 95 \%$ CI: $9-12.2 \%]$.

Staphylococcus aureus is a facultative anaerobic grampositive Staphylococcus bacterium of the mammary gland, which is commonly found also on skin surfaces, nares, vulva (Keefe et al., 1997; Capurro et al., 2010) as well as in the environment. For these reasons, good milking hygiene practices are essential as control measures. In the province of Brescia, apparent herd prevalence of Staph. aureus (calculated as the proportion of herds where at least one BTMS was positive for Staph. aureus out of the total number of herds) was $34.1 \%$ $[34.1 \%=(434 / 1273) \times 100 ; 95 \%$ CI: $31.5-36.7 \%]$ in 2010 , whereas in 2011 it increased to $45.1 \%$ [ $45.1 \%=$ $(624 / 1383) \times 100 ; 95 \%$ CI: $31.5-36.7 \%]$.

In 2012 we carried out the present study to estimate and compare the sensitivity (Se) and specificity (Sp) of bacteriological cultures (BC) and a multiplex real-time PCR (rt-PCR) for Strep. agalactiae and Staph. aureus in BTMS. The BC were a qualitative bacteriological culture (BC1_aga for Strep. agalactiae and BC1_au for Staph. aureus) and a quantitative bacteriological culture (BC2_aga for Strep. agalactiae and BC2_au for Staph. aureus). Because a gold-standard assay was not available, we made use of a 2 latent class approach in a Bayesian framework to estimate the diagnostic accuracies in field conditions.

The study population comprised 165 dairy herds that were found positive on BMTS for Strep. agalactiae during the campaigns 2010 and 2011 of the annual control plan. In most cases, BTMS collected in these herds were positive for Staph. aureus as well, confirming the wide spread of this pathogen. Herd size ranged from 3 to 443 lactating cows per herd, for a total of 8,624 lactating cows. The most common system was free stalls with milking parlor, whereas tie stalls were less common.

From April to June 2012, we collected one BTMS from each herd. At the same time, 8,624 composite milk samples (CMS) were collected from all the lactating cows within those herds and tested for Strep. agalactiae with $\mathrm{BC} 1$ aga to estimate the within-herd prevalence and complete the eradication of Strep. agalactiae in the province.

Bulk-tank milk samples were directly collected by the milk-truck driver according to the following procedure. The milk was agitated in the bulk tank for 15 min before collection, and then an automatic collector was used to sample $120 \mathrm{~mL}$ of milk into a sterilized plastic container. Samples were immediately stored on ice, transported under refrigeration to the laboratory, and maintained at $4 \pm 2{ }^{\circ} \mathrm{C}$ until the analysis. Bacterial analysis was always performed within $24 \mathrm{~h}$ of collection.

For BC1_aga, $10 \mu \mathrm{L}$ of milk was spread in Tallium Kristalviolette Tossin agar (Hauge and Ellingsen, 1953) and incubated for 18 to $24 \mathrm{~h}$ at $37^{\circ} \mathrm{C}$. The blue-violet colonies with $\beta$-hemolytic activity and without esculinhalo were identified as colonies of Strep. agalactiae. A sample was considered positive for Strep. agalactiae when one or more colonies were found on plate.

For BC1_au, $10 \mu \mathrm{L}$ of milk was spread in Baird Parker modified medium with added Rabbit Plasma Fibrinogen ISO-Formulation and incubated first for 48 $\pm 6 \mathrm{~h}$ at $37^{\circ} \mathrm{C}$ and then for a further $24 \pm 6 \mathrm{~h}$ at $4^{\circ} \mathrm{C}$. The black-gray colonies with a whitish area of precipitation plus an opaque zone of coagulation and with or without a transparent area of clarification $(\mathrm{BP}+$ or $\mathrm{BP}-$, respectively) were identified as colonies of Staph. aureus. The isolates were checked for coagulase production and identified using API-20 STAPH (bioMérieux, Marcy l'Etoile, France). A sample was considered positive for Staph. aureus when one or more colonies were found on plate.

For BC2_aga, $100 \mu \mathrm{L}$ of milk was pipetted into the center of a Tallium Kristalviolette Tossin agar plate and then spread on the surface using a sterilized bent glass rod. Samples were plated in parallel and then incubated for 18 to $24 \mathrm{~h}$ at $37^{\circ} \mathrm{C}$. Each sample was analyzed without dilution and in serial dilutions (1:10) up to the $10^{-7}$ dilution. Colonies were identified and counted at the end of incubation. A sample was considered positive for Strep. agalactiae when one or more colonies were counted on the plate.

For BC2_au, $100 \mu \mathrm{L}$ of milk was pipetted into the center of a Baird Parker modified medium with added Rabbit Plasma Fibrinogen ISO-Formulation agar plate and then spread on the surface using a sterilized bent glass rod. Samples were plated in parallel and incubated first for $48 \pm 6 \mathrm{~h}$ at $37^{\circ} \mathrm{C}$ and then for a further $24 \pm$ $6 \mathrm{~h}$ at $4^{\circ} \mathrm{C}$. Each sample was analyzed without dilution and in serial dilutions $(1: 10)$ up to the $10^{-7}$ dilution. Finally, colonies were identified and counted. A sample was considered positive for Staph. aureus when one or more colonies were counted on a plate.

The rt-PCR was developed according to the following protocol. The BTMS were enriched in tryptic soy 
broth at a ratio of 1:2 and then incubated for $24 \pm 2 \mathrm{~h}$ at $37^{\circ} \mathrm{C}$. The DNA extraction was made following the instructions of the QIAamp Cador Pathogen kit (Qiagen, Hilden, Germany) using $400 \mu \mathrm{L}$ of the enrichment so obtained. The primers and probes, with target gene for regulation of D-alanyl-lipoteichoic acid biosynthesis, sensor histidine kinase $(d l t S)$ of Strep. agalactiae and target gene surface protein A (spa) of Staph. aureus, were created according to the guidelines provided by Chiba (Chiba et al., 2009). The PCR was performed using the QuantiTect Virus Master Mix kit (Qiagen) and the DNA extraction Control kit (Bioline, London, UK). The DNA amplification procedure was carried out as follows: $5 \mathrm{~min}$ of denaturation at $95^{\circ} \mathrm{C}, 50$ steps of denaturation at $96^{\circ} \mathrm{C}$ for $15 \mathrm{~s}$ and finally annealing and extension at $60^{\circ} \mathrm{C}$ for $45 \mathrm{~s}$. The cutoff was selected using spiked samples during the development, optimization, and standardization of the assay. A higher cutoff was then arbitrarily selected by the researches to evaluate the potential change of rt-PCR accuracy in case of lower DNA content in BTMS. For Strep. agalactiae the cutoffs were 40 cycle threshold $(\mathbf{C t})$ and $50 \mathrm{Ct}$, whereas for Staph. aureus, they were $38 \mathrm{Ct}$ and $50 \mathrm{Ct}$.

To estimate the diagnostic accuracy of the 3 assays, we used the Bayesian 2 latent class model proposed by Branscum (Branscum et al., 2005). In our study, the 2 latent class definitions were that of infected herd (for Strep. agalactiae or Staph. aureus) and that of infectionfree herd. Because the $2 \mathrm{BC}$ were based on a common biological phenomenon, we considered the possibility that those test results could be conditionally dependent (Gardner et al., 2000). As suggested by Dendukuri and Joseph (2001), we modeled this condition in terms of 2 pairwise covariances, one for the dependence between the results of $\mathrm{BC}$ in infected herds and one for that in infection-free herds.

To ensure a condition for model identifiability, the number of degrees of freedom of the model must be greater than the number of parameters to be estimated. The term "unconstrained parameters" refers to those parameters for which neither informative priors nor stochastic constraints are defined in the model. In our study, we had 10 parameters; that is, $3 \mathrm{Se}, 3 \mathrm{Sp}, 2$ prevalences, and the 2 pairwise covariances among the BC. We modeled the 2 pairwise covariances as a uniform distribution on the interval ( 0 , upper bound) to force them to be positive (Dendukuri et al., 2009). In this way we remained with 8 unconstrained parameters (the $3 \mathrm{Se}, 3 \mathrm{Sp}$, and the 2 prevalences). However, according to the equation $q=M(2 k-1)$ (Jones et al., 2010), where $q$ is the number of degrees of freedom, $M$ the number of populations, and $k$ the number of tests, we still had only 7 degrees of freedom available.
To increase the number of degrees of freedom, we divided our sample in 2 subpopulations for which we assumed different herd prevalence (Hui and Walter, 1980). For this purpose, we chose the threshold of 20 or less cows in lactation on the farm at sampling on the basis of expertise provided by the Italian Reference Centre for Bovine Milk Quality in Brescia. After this step, the total number of degrees of freedom increased to 14 , exceeding the number of unconstrained parameters (8) that were modeled using noninformative $\beta$ distributions.

For both the pathogens, we ran the same model with and without the pairwise covariances, to verify whether a simpler model could fit the data equally well. The deviance information criterion value (DIC; Spiegelhalter et al., 2002) and the Bayesian P-value (Gelman et al., 1995) were used to select the best model and evaluate goodness of fit.

Eventually, the selected models for Strep. agalactiae and Staph. aureus were evaluated using $2 \mathrm{Ct}$ for the PCR, as stated previously. Models were run using 2 independent chains with different initial values for 410,000 iterations, with burn-in of 10,000 iterations and a thin factor equal to 50 . This gave a total of 16,000 samples from the posterior distributions that were used for inference. Model convergence was evaluated according to the guidelines of Toft (Toft et al., 2007) as well as 4 convergence diagnostics available in the $\mathrm{R}$ package BOA (Bayesian Output Analysis, ver. 1.1.7-2, $\mathrm{R}$ Core Team, Vienna, Austria), namely the Geweke, Gelman and Rubin, Heidelberger and Welch, and Raftery and Lewis diagnostics. Models were implemented in WinBUGS 1.4.3 software (MRC Biostatistics Unit, Cambridge, UK 1996-2012).

A total of 165 BTMS were available for Strep. agalactiae, whereas only 157 were available for Staph. aureus because 8 BTMS were contaminated and excluded from the analysis. A total of 8,624 individual milk samples were collected from all the dairy cows in lactation and tested for Strep. agalactiae using BC1_aga. For 10 herds it was not possible to track down the results on CMS, and so they were excluded by further analysis. For the remaining 155 herds, Table 1 reports the number of infected herds where at least one CMS was positive for Strep. agalactiae and the number of infected herds where the apparent within-herd prevalence was equal or higher than 10, 20, and $30 \%$, respectively, in the 2 subpopulations. Table 2 reports the cross-classification of test results for Strep. agalactiae and Staph. aureus in the 2 subpopulations at the 2 prespecified Ct.

For Strep. agalactiae, the difference in the DIC value between the model with the covariances and the model without the covariances was 1 at $40 \mathrm{Ct}$ and 1.7 at 50 
Table 1. Results of BC1_aga (qualitative bacteriological culture for Streptococcus agalactiae) on composite milk samples (CMS)

\begin{tabular}{lcccccc}
\hline & & & & \multicolumn{2}{c}{$\begin{array}{c}\text { Number of infected herds by } \\
\text { within-herd prevalence }\end{array}$} \\
\cline { 5 - 7 } Subpopulation & $\begin{array}{c}\text { Number } \\
\text { of herds }\end{array}$ & $\begin{array}{c}\text { Between-herd } \\
\text { prevalence }^{1}(\%)\end{array}$ & $\begin{array}{c}\text { Number of } \\
\text { infected herds }\end{array}$ & $\geq 10 \%$ & $\geq 20 \%$ & $\geq 30 \%$ \\
\hline Small-size herds $^{3}$ & 54 & 59.3 & 32 & 31 & 28 & 21 \\
Large-size herds $^{4}$ & 101 & 54.5 & 55 & 39 & 26 & 14 \\
Total & 155 & 56.1 & 87 & 70 & 54 & 35 \\
\hline
\end{tabular}

${ }^{1}$ Herds where at least one CMS was positive for Strep. agalactiae.

${ }^{2}$ Number of infected herds with prevalence equal or higher than 10,20 , and $30 \%$, respectively, according to test results on CMS.

${ }^{3}$ Small-size herds: 20 or less lactating cows.

${ }^{4}$ Large-size herds: 21 or more lactating cows.

Table 2. Test results of qualitative bacteriological culture (BC1), quantitative bacteriological culture (BC2), and real-time PCR (rt-PCR) for Streptococcus agalactiae (aga) and Staphylococcus aureus (au) at different cycle thresholds (Ct; data reported as in Branscum et al., 2005)

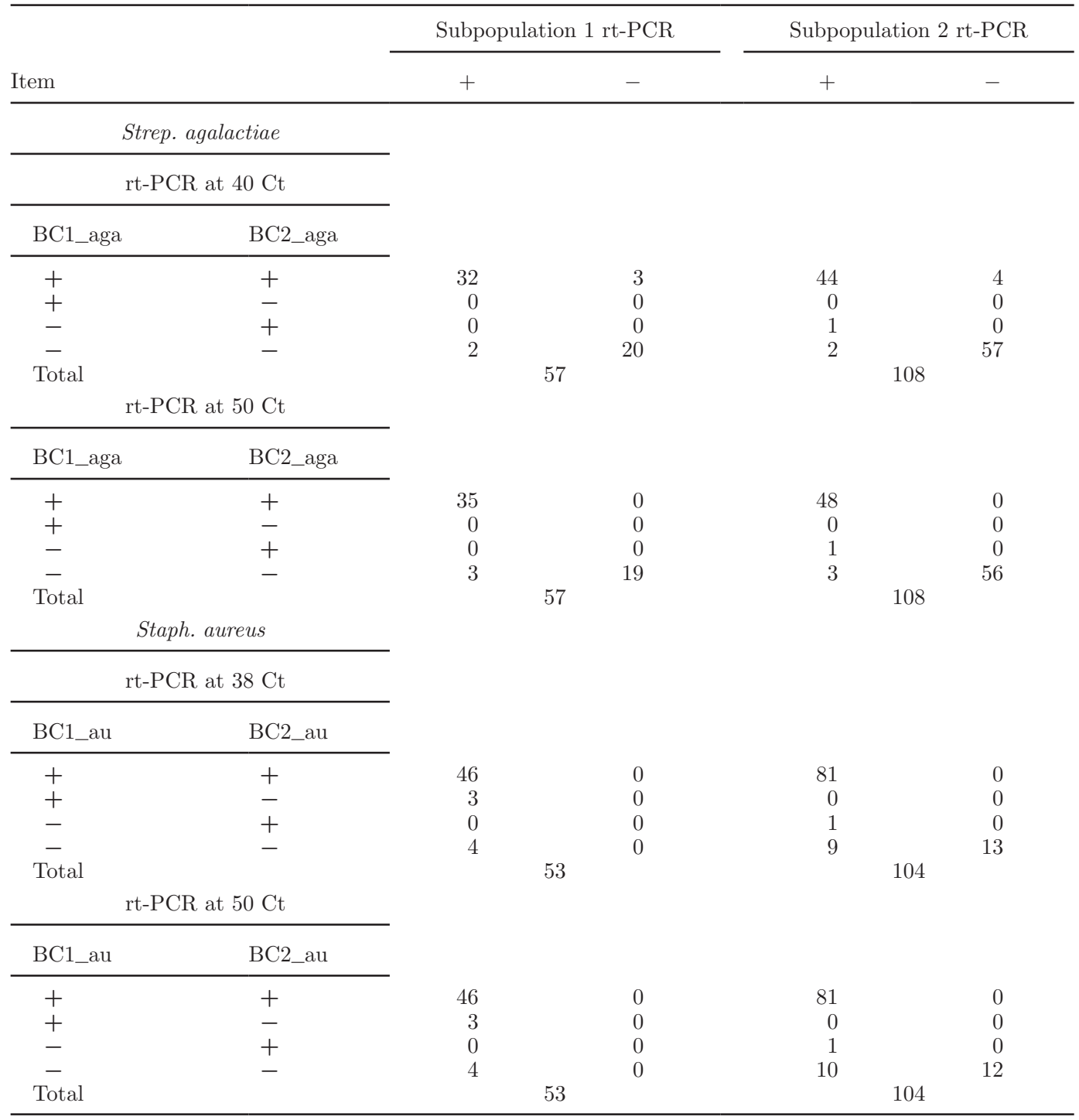


Ct, whereas for Staph. aureus the difference was 3.9 at $38 \mathrm{Ct}$ and 4.4 at $50 \mathrm{Ct}$. Given that a rule of thumb suggests that a difference greater than 3 in DIC value should be regarded as important (Spiegelhalter et al., 2002), we selected the model without covariances for Strep. agalactiae and the model with the covariances for Staph. aureus. Table 3 reports the posterior esti- mates of mean, median, and $95 \%$ posterior credible interval $(\mathbf{9 5 \%}$ PCI $)$ of the relevant parameters (Se, Sp, prevalence, and, when suitable, the covariances) as well as goodness-of-fit statistics (DIC and Bayesian $P$-value). Visual inspection of trace plots suggests that convergence was arguably reached for all the parameters in the models. The Monte Carlo error was largely

Table 3. Herd prevalence in the 2 subpopulations, estimates of sensitivity (Se) and specificity (Sp) of the 3 assays, and goodness-of-fit statistics at the 2 prespecified cutoffs [cycle threshold (Ct)] for Streptococcus agalactiae (aga) and Staphylococcus aureus (au)

\begin{tabular}{|c|c|c|c|}
\hline Variable $^{1}$ & Median & Mean & $95 \%$ PCI \\
\hline \multicolumn{4}{|c|}{$\begin{array}{l}\text { Strep. agalactiae - model without the covariance terms } \\
\text { rt-PCR at } 40 \mathrm{Ct}\end{array}$} \\
\hline Prevalence subpopulation 1 & 0.61 & 0.61 & $0.48-0.73$ \\
\hline Prevalence subpopulation 2 & 0.45 & 0.45 & $0.36-0.55$ \\
\hline Se BC1_aga & 0.98 & 0.98 & $0.94-1.00$ \\
\hline Se BC2_aga & 0.99 & 0.99 & $0.96-1.00$ \\
\hline Se PCR & 0.92 & 0.92 & $0.85-0.97$ \\
\hline Sp BC1_aga & 0.99 & 0.99 & $0.96-1.00$ \\
\hline Sp BC2_aga & 0.99 & 0.99 & $0.95-1.00$ \\
\hline Sp PCR & 0.94 & 0.94 & $0.88-0.98$ \\
\hline Bayes $P$-value & 0.66 & & \\
\hline DIC & 40.2 & & \\
\hline \multicolumn{4}{|l|}{ rt-PCR at $50 \mathrm{Ct}$} \\
\hline Prevalence subpopulation 1 & 0.61 & 0.61 & $0.48-0.73$ \\
\hline Prevalence subpopulation 2 & 0.45 & 0.45 & $0.36-0.55$ \\
\hline Se BC1_aga & 0.98 & 0.98 & $0.94-1.00$ \\
\hline Se BC2_aga & 0.99 & 0.99 & $0.96-1.00$ \\
\hline Se PCR & 0.99 & 0.99 & $0.96-1.00$ \\
\hline Sp BC1_aga & 0.99 & 0.99 & $0.96-1.00$ \\
\hline Sp BC2_aga & 0.99 & 0.99 & $0.95-1.00$ \\
\hline Sp PCR & 0.92 & 0.91 & $0.85-0.96$ \\
\hline Bayes $P$-value & 0.60 & & \\
\hline DIC & 35.4 & & \\
\hline \multicolumn{4}{|c|}{$\begin{array}{l}\text { Staph. aureus - model with the covariance terms } \\
\text { rt-PCR at } 38 \mathrm{Ct}\end{array}$} \\
\hline Prevalence subpopulation 1 & 0.97 & 0.96 & $0.86-1.00$ \\
\hline Prevalence subpopulation 2 & 0.82 & 0.82 & $0.72-0.90$ \\
\hline Se BC1_au & 0.94 & 0.94 & $0.87-0.99$ \\
\hline $\mathrm{Se} \mathrm{BC} 2 \_\mathrm{au}$ & 0.92 & 0.92 & $0.85-0.98$ \\
\hline Se PCR & 0.99 & 0.99 & $0.97-1.00$ \\
\hline Sp BC1_au & 0.95 & 0.93 & $0.76-1.00$ \\
\hline Sp BC2_au & 0.93 & 0.92 & $0.74-1.00$ \\
\hline Sp PCR & 0.67 & 0.68 & $0.38-0.97$ \\
\hline Covariance in infected herds & 0.05 & 0.05 & \\
\hline Covariance in not-infected herds & 0.01 & 0.03 & \\
\hline Bayes $P$-value & 0.34 & & \\
\hline DIC & 39.5 & & \\
\hline \multicolumn{4}{|l|}{ rt-PCR at $50 \mathrm{Ct}$} \\
\hline Prevalence subpopulation 1 & 0.97 & 0.96 & $0.86-1.00$ \\
\hline Prevalence subpopulation 2 & 0.82 & 0.82 & $0.72-0.91$ \\
\hline Se BC1_au & 0.94 & 0.93 & $0.86-0.99$ \\
\hline Se BC2_au & 0.92 & 0.92 & $0.85-0.98$ \\
\hline Se PCR & 0.99 & 0.99 & $0.97-1.00$ \\
\hline Sp BC1_au & 0.94 & 0.93 & $0.75-1.00$ \\
\hline Sp BC2A_au & 0.93 & 0.91 & $0.73-1.00$ \\
\hline Sp PCR & 0.63 & 0.64 & $0.34-0.96$ \\
\hline Covariance in infected herds & 0.05 & 0.05 & \\
\hline Covariance in not-infected herds & 0.02 & 0.03 & \\
\hline Bayes $P$-value & 0.34 & & \\
\hline DIC & 39.3 & & \\
\hline
\end{tabular}

${ }^{1}$ rt-PCR: real-time PCR; $\mathrm{BC} 1$ : qualitative bacteriological culture; $\mathrm{BC} 2$ : quantitative bacteriological culture; 95\% PCI: $95 \%$ posterior credible interval; subpopulation 1: 20 or less lactating cows on the farm at sampling; subpopulation 2: 21 or more lactating cows on the farm at sampling; DIC: deviance information criterion. 
lower than $5 \%$ of the sample standard deviation for all the parameters. Also results of the 4 convergence diagnostic tests did not give evidence of convergence failure, except in the case of the Geweke diagnostics for the Se of BC1_aga (Strep. agalactiae) when the PCR was set at $40 \mathrm{Ct}$, and the prevalence of Staph. aureus in the first subpopulation at $38 \mathrm{Ct}$.

We used a latent class model to estimate the ability of 3 assays to classify dairy herds in infected or not infected according to the contamination of BTMS. However, the definition of "infected herd" is not unique, because it can go through many intermediate states. For instance, a herd can be defined "highly infected" when many cows are shedding high number of viable bacteria with milk, but it can be also defined "lightly infected" when cows just pass nonviable bacteria or DNA fragments (Mahmmod et al., 2012).

In the case of highly infected herds (that is, many cows shedding high numbers of viable bacteria in BTMS), BC may be superior in accuracy to PCR assays (Mweu et al., 2012). Results of our study (Table 3) suggest that the BC for Staph. aureus and Strep. agalactiae could be superior to rt-PCR. We believe that the main type of infection being present in our study population was that of "highly infected herd" for Strep. agalactiae and Staph. aureus. This hypothesis is supported by historical data and epidemiological considerations. First, we included in the study herds that have had a history of IMI and where positive BTMS for Staph. aureus and Strep. agalactiae had been found in the previous years. Second, results of Strep. agalactiae presence in CMS collected in parallel suggested a high level of infection for Strep. agalactiae within the herds. In fact, assuming that the condition of high infection of a herd could be associated to a within-herd prevalence of $20 \%$ or more, almost all of the infected small size herds (28 out of 32 ) and about half of the large-size herds (26 out of 55 ) of the study population were in this condition (Table 1). Finally, when we increased the $\mathrm{Ct}$, the estimated herd prevalences and the diagnostic accuracy of the assays (rt-PCR + BC) did not change substantially (Table 3). Conversely, if accuracies (or herd prevalences) had instead changed, this would have meant that the assays were targeting different types of infection in the study population, for instance from highly infected herds at the lowest $\mathrm{Ct}$ to a combination of heavily and slightly infected herds increasing the Ct (Mweu et al., 2012).

Regarding the statistical model, the final model for Strep. agalactiae did not include the covariances, whereas that for Staph. aureus did. The inclusion of the covariances in the model for Staph. aureus did not change the diagnostic accuracy of the assays, except for the Sp of the PCR, that significantly increased at both Ct. Finally, the posterior distribution of the cova- riance in infected herds was bimodal, with one mode at zero and one at a very low positive value, whereas the covariance in infection-free herds was unimodal, with the mode approximately at zero. This suggests that, even if the model for Staph. aureus accounted for the dependence between the test results of the $\mathrm{BC}$, this was weak.

The posterior medians of Se and Sp of rt-PCR for Strep. agalactiae were generally lower than that of the $\mathrm{BC}$, regardless the cutoff (Table 3). The corresponding $95 \% \mathrm{PCI}$ of the 3 assays overlapped. We point out that overlapping $95 \% \mathrm{PCI}$ is a condition for which it is not necessarily true that estimates are not significantly different. Then, as previously mentioned, BC could be really superior to rt-PCR in highly infected herds.

The accuracy of rt-PCR was slightly lower than the accuracy of a similar PCR reported in a recent study (Mweu et al., 2012). In that study, the estimated herd prevalences were extremely low, and this indicates a very different study population; as diagnostic test properties may change with disease prevalence (Leeflang et al., 2009), this may explain such difference. Also the precision of our estimates was lower than that reported by Mweu et al. (2012), but this could be due to the small sample size and to the small difference between the prevalences of the 2 subpopulations in our study (Toft et al., 2005).

Regarding Staph. aureus, the median value of the Se of the rt-PCR was higher than that of the $\mathrm{BC}$, but that of the Sp was much lower, regardless the cutoff (Table $3)$. Also in this case, the 95\% PCI overlapped. The $95 \%$ PCI of the Sp of the rt-PCR was particularly large. This could be due to the small sample size (157 herds) but also to the high prevalence in the 2 subpopulations. These conditions probably did not provide sufficient data on healthy herds to reduce uncertainty.

In conclusion, our study confirms that BC and rtPCR are suitable to detect Strep. agalactiae and Staph. aureus in heavily infected herds. The rt-PCR with $\mathrm{Ct}$ values higher than 40 for Strep. agalactiae and 38 for Staph. aureus could represent an appealing alternative because of speed and ease of use, and results should be always confirmed by bacteriological culture carried out on BTMS and possibly on CMS.

\section{ACKNOWLEDGMENTS}

This preliminary study was supported by the Italian Ministry of Health within the project "Messa a punto di tecniche molecolari per la rilevazione di agenti zoonosici e di mastiti contagiose in campioni di latte bovino" (PRC 2011/011). The authors thank Maura Ferrari, Riccardo Villa, Cristina Baiguera, and Antonella Posante for the precious help in developing and 
applying real-time PCR and Frank Welcome from Cornell University (Ithaca, NY) for English text revision.

\section{REFERENCES}

Branscum, A. J., I. A. Gardner, and W. O. Johnson. 2005. Estimation of diagnostic-test sensitivity and specificity through Bayesian modeling. Prev. Vet. Med. 68:145-163.

Capurro, A., A. Aspán, H. E. Unnerstad, W. K. Persson, and K. Artursson. 2010. Identification of potential sources of Staphylococcus aureus in herds with mastitis problems. J. Dairy Sci. 93:180-191.

Chiba, N., S. Y. Murayama, M. Morozumi, E. Nakayama, T. Okada, S. Iwata, K. Sunakawa, and K. Ubukata. 2009. Rapid detection of eight causative pathogens for the diagnosis of bacterial meningitis by real-time PCR. J. Infect. Chemother. 15:92-98.

Dendukuri, N., A. Hadgu, and L. Wang. 2009. Modeling conditional dependence between diagnostic tests: A multiple latent variable model. Stat. Med. 28:441-461.

Dendukuri, N., and L. Joseph. 2001. Bayesian approaches to modeling the conditional dependence between multiple diagnostic tests. Biometrics 57:158-167.

Eberhart, R. J., R. J. Harmon, D. E. Jasper, R. P. Natzke, S. C. Nickerson, J. K. Reneau, E. H. Row, K. L. Smith, and S. B. Spencer. 1987. Current Concepts of Bovine Mastitis. 3rd ed. Natl. Mastitis Counc. Inc., Arlington, VA

Gardner, I. A., H. Stryhn, P. Lind, and M. T. Collins. 2000. Conditional dependence between tests affects the diagnosis and surveillance of animal diseases. Prev. Vet. Med. 45:107-122.

Gelman, A., J. B. Carlin, H. S. Stern, and D. B. Rubin. 1995. Bayesian Data Analysis. Chapman Hall, London, UK.

Hauge, S., and J. K. Ellingsen. 1953. Selective agar medium (TKT Medium) for demonstration of group B streptococci in samples of producer milk. Nord. Vet. Med. 5:539-547.

Hui, S. L., and S. D. Walter. 1980. Estimating the error rates of diagnostic tests. Biometrics 36:167-171.
Jones, G., W. O. Johnson, T. E. Hanson, and R. Christensen. 2010. Identifiability of models for multiple diagnostic testing in the absence of a gold standard. Biometrics 66:855-863.

Keefe, G. P., I. R. Dohoo, and E. Spangler. 1997. Herd prevalence and incidence of Streptococcus agalactiae in the dairy industry of Prince Edward Island. J. Dairy Sci. 80:464-470.

Leeflang, M. M. G., P. M. M. Bossuyt, and L. Irwig. 2009. Diagnostic test accuracy may vary with prevalence: Implications for evidencebased diagnosis. J. Clin. Epidemiol. 62:5-12.

Mahmmod, Y. S., N. Toft, J. Katholm, C. Grønbæk, and I. C. Klass. 2012. Estimation of test characteristics of real-time PCR and bacterial culture for diagnosis of subclinical intramammary infections with Streptococcus agalactiae in Danish dairy cattle in 2012 using latent class analysis. Prev. Vet. Med. 109:264-270.

Mweu, M. M., N. Toft, J. Katholm, and S. S. Nielsen. 2012. Evaluation of two herd-level diagnostic tests for Streptococcus agalactiae using a latent class approach. Vet. Microbiol. 159:181-186.

Schukken, Y. H., J. Hertl, D. Bar, G. J. Bennett, R. N. Gonzales, B. J. Rauch, C. Santisteban, H. F. Schulte, L. Tauer, F. L. Welcome, and Y. T. Gröhn. 2009. Effects of repeated gram-positive and gram-negative clinical mastitis episodes on milk yield loss in Holstein dairy cows. J. Dairy Sci. 92:3091-3105.

Smith, K. L., and J. S. Hogan. 1995. Epidemiology of mastitis. Proc. 3rd Int. Mastitis Sem., Tel Aviv, Israel, S6:3-12.

Spiegelhalter, D. J., N. G. Best, B. P. Carlin, and A. Van der Linde. 2002. Bayesian measures of model complexity and fit (with discussion). J. R. Stat. Soc. B 64:583-616.

Toft, N., J. Akerstedt, J. Tharaldsen, and P. Hopp. 2007. Evaluation of three serological tests for diagnosis of Maedi-Visna virus infection using latent class analysis. Vet. Microbiol. 120:77-86.

Toft, N., E. Jørgensen, and S. Højsgaard. 2005. Diagnosing diagnostic tests: Evaluating the assumptions underlying the estimation of sensitivity and specificity in the absence of a gold standard. Prev. Vet. Med. 68:19-33. 